\title{
Article
}

\section{Internet Facilitated Rape: A Multivariate Model of Offense Behavior}

\author{
Almond, Louise, Mcmanus, Michelle Ann and Chatterton, Hannah \\ Available at http://clok.uclan.ac.uk/18533/ \\ Almond, Louise, Mcmanus, Michelle Ann ORCID: 0000-0002-0095-1071 and \\ Chatterton, Hannah (2020) Internet Facilitated Rape: A Multivariate Model of \\ Offense Behavior. Journal of Interpersonal Violence, 35 (21-22). pp. 4979- \\ 5004. ISSN 0886-2605
}

It is advisable to refer to the publisher's version if you intend to cite from the work. http://dx.doi.org/10.1177/0886260517718187

For more information about UCLan's research in this area go to http://www.uclan.ac.uk/researchgroups/ and search for < name of research Group>.

For information about Research generally at UCLan please go to http://www.uclan.ac.uk/research/

All outputs in CLoK are protected by Intellectual Property Rights law, including Copyright law. Copyright, IPR and Moral Rights for the works on this site are retained by the individual authors and/or other copyright owners. Terms and conditions for use of this material are defined in the policies page.

\section{CLoK}

Central Lancashire online Knowledge www.clok.uclan.ac.uk

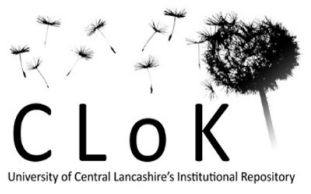




\section{Internet Facilitated Rape: A Multivariate Model of Offense Behavior}

Dr Louise Almond ${ }^{1}$

School of Psychology, University of Liverpool, Eleanor Rathbone Building, Bedford Street South, L69 7ZA, email: lalmond@ liverpool.ac.uk tel: 0044 (0)151 7946708

Dr Michelle McManus

Policing and Criminal Investigation, School of Forensic and Investigative Science, University of Central Lancashire, Preston, PR1 2HE, email: mamcmanus@uclan.ac.uk tel: 0044 (0)1772 894154

Hannah Chatterton

School of Psychology, University of Liverpool, Eleanor Rathbone Building, Bedford Street South, L69 7ZA. H.Chatterton@ liverpool.ac.uk

\footnotetext{
${ }^{1}$ Corresponding author
} 


\section{Introduction}

The Internet has transformed our everyday lives, it has revolutionised the way we communicate and the way we socialise. Moreover, the Internet is becoming one of the most popular venues to meet new peers and new partners (Rosenfeld \& Thomas, 2012). Recent statistics reported by the National Crime Agency (2016) state that one in three relationships now start online. The multitude of platforms that facilitate the online connection and communication with strangers is predicted to continue to increase (National Crime Agency, 2016) with apps such as Tinder reporting to have 50 million registered users and 8 billion connections made (The Guardian, 2015), and specific internet dating websites such as Plenty of Fish, with a reported 88 million registered users, of which 10 million 'come together to connect, flirt, and share with each other' everyday (Plenty of Fish, 2016). This contemporary style of meeting and engaging with strangers offers predators an easy way to browse, search and select their victims. Additionally, the privacy provides offenders with the space to manipulate, groom and seduce victims into offline encounters.

Previous sexual research investigating the use of the Internet has predominantly focused on the predation of child victims (Walsh \& Wolak, 2005; Wolak, Finkelhor \& Mitchell, 2004; Wolak, Finkelhor, Mitchell \& Ybarra, 2008). Statistics regarding the prevalence of these child directed crimes has shown increases in the number of individuals and offenses of indecent images of children and child sexual offenses within the US (Wolak, Finkhelhor \& Mitchell, 2011) and within the UK (McManus \& Almond, 2014). The reasons for the increase in child sexual offenses is still under debate, with the ease of access, availability of content and perceived anonymity (Cooper, 2002) alongside increased awareness and reporting with the assistance of specialised child protection and law enforcement agencies, such as Child Exploitation Online Centre (CEOP). Furthermore, existing research focuses primarily on analysing the online transcriptions presented between the victim and the offender (McManus, Almond, Cubbon, Boulton \& Mears, 2016), identifying how predators select their victims (Noll, Shenk, Barnes \& Putnam, 2009) and lure them offline and into sexual encounters (Malesky, 2007). This research allows the development of 
targeted campaigns informing young people of the risks involved in online communication with strangers, however, this may be limited in terms of pragmatic value to criminal investigations. Whilst the incidence of Internet Facilitated Rape (IFR) represents a serious and significant issue, as reported by the National Crime Agency (2016) there has been a six-fold increase in the number of these offenses from 2009 to 2014, there is a lack of research which has examined adult victims in any detail.

In response to this significant increase in IFR, the National Crime Agency have recently produced a report examining the trends between online dating and serious sexual assaults (National Crime Agency, 2016). Summarising the report, they pull out a number of key findings from collecting data from UK police forces, with additional in-depth analysis from Serious Crime Analysis Section (SCAS). One key finding relates to what they term as a 'new type of sexual offender', as these rapists who initially met their victims online, differed from other stranger rapists and serious sexual assault cases, in that IFR offenders had less criminal convictions. When these IFRs offenders did have criminal convictions, these were likely to be for less serious offending, for example, minor road traffic offenses. The report discusses the different environment created by the internet, which allows the dating process to speed up the relationship process. Trust is built up quickly, often with sexual messages and disclosures made before face-to-face meetings. This increased trust is evidenced through victims engaging in risky behavior, such as agreeing to meet within a private residence, or moving the date to a private residence. The report indicated that $72 \%$ of victims were sexually assaulted within a residence, with $41 \%$ initially meeting at a residence. This mismatch of expectations built from online communications prior to face-to-face contact may lead the offender to believe that the victim consents to sexual activity.

As suggested within this report, these IFR's were showing different behaviors to stranger rapists and other serious sexual offenders in their previous offending behaviors. Whether these differences also extend to the crime scene itself (where the rape took place) is unknown. Whether behavioral subgroups exist within the category of IFR is also presently unknown, even though it is 
acknowledged that there are various platforms used for IFR (National Crime Agency, 2016), no research has looked to differentiate within this population. However, if the group can be deconstructed into smaller and more behaviorally consistent counterparts, researchers could form a clearer and more organised understanding of behavior exhibited within the IFR crime scene (note: not including the behavior and online communication prior to the rape). This coordinated understanding may direct the development of a more precise and reliable classification model, helping to better understand IFR offenses.

Concentrating on overt crime scene behaviors allows psychologists to develop scientifically valid and reliable profiles that have true pragmatic value to law enforcement agencies. Previous research on non-IFR has analysed the overt crime scene behaviors displayed by perpetrators to provide empirical research regarding the heterogeneity of these offenders (Almond, McManus \& Ward, 2013; Canter, Bennell \& Alison, 2003; Santilla, Junkkila \& Sandnabba, 2005). This research has identified an underlying structure of sex offenses, illustrating different behavioral themes of rape. Themes can classify assaults and have previously proved useful in differentiating between offenses and offenders (Yokota \& Canter, 2004).

As situational factors may determine the use or absence of specific behaviors, an offender's conduct can be better understood in relation to other related behaviors and within a behavioral theme (Canter \& Young, 2003). Although behavioral classification models differ slightly in their general themes and their labels, when taken together, research suggests that rapists in general can be divided into three main themes that reflect the offender's level of violence, interpersonal involvement and criminal sophistication (Corovic, Christianson \& Bergman, 2012; Park, Schlesinger, Pinizzotoo \& Davis, 2008).

\section{Criminal Sophistication}


Criminal sophistication refers to the offender's ability to avoid detection; knowledge of scientific and technological advances may culminate in 'criminally aware' behavior (Hazelwood \& Burgess, 2001). Offenders in this theme may commit other non-sexual crimes such as burglary or robbery at the time of the offense. Serial offenders commonly demonstrate behavior that suggests criminal sophistication, such as gagging, or taking steps to ensure no discriminating evidence can be obtained (Park et al., 2008). Davies' (1997) findings resulted in similar conclusions, showing 'criminally aware' behavior was more common to offenders who held multiple convictions for sexual offenses. This category is reflected in Canters (1994) 'victim as object' theme, where the victim is used solely for the offender's instrumental as well as sexual gratification i.e. steals property from the victim. As a result of these studies it is possible to hypothesise which IFR offense behaviours relate to this Criminal Sophistication theme (See Table 1)

\section{Interpersonal Involvement}

This theme refers to an offender's attempt to seek intimacy with the victim and in a distorted way address his sense of emptiness (Marshall, 1989). The desire for intimacy has also been defined as a primary motivation for rape (Marshall, 1989). In support of this, sex offenders have been found to be lonelier and more deficient in intimacy than other offenders (Seidman, Marshall, Hudson \& Robertson, 1994). Behaviors in this theme include complimenting and reassuring the victim, and reciprocal sexual behaviors. Behavioral themes of 'involvement' have been identified by many researchers (Almond et al, 2013; Canter et al., 2003; Santilla et al., 2005) and are reflected in Canter's (1994) 'victim as person' theme, in which the offender attempts to form a pseudo-intimate relationship with the victim. As a result of these studies it is possible to hypothesise which IFR offense behaviours relate to this Interpersonal Involvement theme (See Table 1)

\section{Violence}


The theme of violence has arisen throughout literature on rape in a variety of different forms. Anger has been identified as a central motivating factor in the act of rape by Groth et al. $(1977 ; 1979)$, this theme is characterised by physical brutality and excessive amounts of violence and force (Knight \& Prentky, 1990; Palermo, 2003). A multidimensional scaling (MDS) analysis of rape conducted by Canter et al. (2003) provides evidence for a behavioral theme of 'hostility', encompassing the use of excessive violence (Santilla et al., 2005). Similar behaviors are also found in Canter's (1994) 'victim as vehicle' theme, in which the victim is used as a vehicle to vent the offender's anger or frustration. As a result of these studies it is possible to hypothesise which IFR offense behaviours relate to this Violence theme (See Table 1)

\begin{abstract}
Aims
As outlined within the recent National Crime Agency (2016) report, there is a significant and increasing prevalence of stranger rapes that initiated their sexual offence through use of the internet (IFR). With a wealth of research regarding the use of the Internet within child sexual offending, there is a lack of research that has explored this with adult victims. With initial reports indicating differences between IFR and stranger rapists/serious sexual assaults in terms of their previous criminal history (National Crime Agency, 2016), further research is needed to explore other factors that will increase our understanding of IFR, such as the platform used when initiating communication with victims, and the behaviors displayed within the rape itself. Therefore, the current study seeks to first explore the various platforms used by IFR to solicit their victims (adverts [sexual], dating sites, internet chat rooms, social networking sites, unknown), examining whether any differences in discreet behaviors exist (Aim 1). Before doing any exploration of the IFR sample compared to other sexual offending samples, it is important to first identify whether behavioral differences existed when differentiating by the various platforms used. If differences are identified, then further analyses will need to divide the IFR sample and consider each platform group separately.
\end{abstract}


In order to refine our understanding of IFR, researchers also need to identify actions that may define and differentiate this offense type when compared to non-Internet facilitated rape (nonIFR) offenses. By comparing the actions of IFRs to those displayed by non-IFRs, researchers can identify if there are any distinct behavioral tendencies typical to offense types in terms of discrete behaviors (aim 2) and themes of behavior (aim 3-Table 1).

Hazewood and Burgess (2001) argued that an offenders' method of approaching a victim potentially effects their subsequent crime scene behaviors. The literature identifies two very different approach styles, the confidence approach where the offender starts a conversation or tries to interact with the victim before attacking them, and the surprise approach where the offender attacks the victim with no prior interaction (Canter \& Youngs, 2008). As IFR would be deemed to have used a confidence approach, this study will utilise two non-IFR samples 1) confidence approach and 2) surprise approach, to control for the potentially mediating factor of approach style. This understanding could assist law enforcement agencies in distinguishing between offenses and offenders, providing a better understanding of the crime, as the crime scene behaviors that do not take into account the behavior and communication prior to the rape.

\section{Method}

\section{Sampling}

The sample consisted of all single IFR cases recorded from 2003 to 2014 and two comparative samples of age-matched non-IFR cases from the same time period, all held on the UK Serious Crime Analysis Section (SCAS) database. Offenders were matched for age and gender to reduce the potential confounding effect these factors may have had on the results. The first sample included cases where the Internet was used in a confidence approach $(n=144)$. Here the offender gained the victim's confidence before the attack, specifically where the offender 'arranged to meet' or 'befriended' the victim online. The first comparative sample was also confined to cases where a confidence approach was utilised by the offender, but where the Internet was not used within the 
offense $(n=144)$. The second comparative sample was confined to cases where a surprise approach was utilised by the offender, but again the Internet was not used within the offense $(n=144)$. This was done to enable comparisons to be made across the full range of stranger rapists. All rape cases will be limited to those committed by male perpetrators against female stranger victims (including stranger 1 cases, where the offender was a stranger to the victim and stranger2 cases, where the offender is known by the victim to a limited degree), with offenders and victims being's aged 16 years and above.

The average age of the IFR victim was 27.24 years $(S D=9.60)$. The average age of the IFR offender was 31.70 years $(\mathrm{SD}=9.86)$. No multiple offenses by the same offender were included in the analysis to ensure that no extra weighting was given to offenders who displayed particular behaviors through multiple offenses; this method was also employed by Canter et al. (2003).

Sampling within the SCAS dataset provides researchers with data that is both nationally representative and detailed. Data of this standard will elicit informed and reliable results, demonstrating a generalisable and comprehensive understanding of behavior typical to this unique group of offenders.

\section{Variables}

Pre-coded data was obtained from UK's SCAS. Police cases files, which meet specific criteria, are forwarded to SCAS, analysts then code the information onto the ViCLAS (Violent Crime Linkage Analysis System) database which allows specific information about the offender, and the offence to be recorded. This study was granted access to thirty-eight crime scene actions that had previously been identified as pertaining to stranger rape cases (see Table 1), these actions were pre-coded as either present or absent for each offense by SCAS, this dichotomous approach is used to ensure maximum clarity and reliability when using data which was not originally collected for research purposes (Almond et al, 2013). 
Table 1: Table 1. Behavioral variables under their predicted theme with supporting literature insert here

\section{Data analysis}

Chi-squared tests were used to examine whether any significant differences existed between:

(i) Social media IFR and Dating website IFR and

(ii) (a) IFR and confidence

b) IFR and surprise

c) confidence and surprise

In terms of the Thirty-eight discrete crime scene actions, due to multiple comparisons Bonferroni Holn corrections $(\mathrm{p}<.0001-0.003)$ were implemented to reduce the possibility of producing false positive results (Field, 2013).

A multi-dimensional scaling technique called smallest space analysis (SSA) was then conducted on the IFR sample to elucidate the underlying structure of offense behaviors. This technique has been adopted previously by research investigating the behavioral themes of non-IFR offenses (e.g. Santilla et al., 2005). SSA's measure the association between each crime scene behavior and every other crime scene behavior. As with previous studies, behaviors that occurred in less than $5 \%$ of cases were excluded from this analysis, as were variables that occurred in more than $70 \%$ of cases as these variables were committed by the majority of offenders and therefore would not assist researchers in differentiating between assaults (Almond et al, 2013). Consequently, 12 behaviors were excluded from the SSA. Jaccard's coefficient was employed as it does not take into account joint non-occurences. This is regarded as the most appropriate measure when dealing with police data due to its unverifiable nature, where there is a possibility that behaviors were not recorded when they were in fact present (Canter et al., 2003). The relationships between variables were then visually represented, where behaviors more heavily correlated are situated closer together in real geometric space. This spatial configuration elucidates any hidden structures or relationships 
between variables, demonstrating the underlying structure of crime scene actions, allowing thematic differentiation to be defined (Almond et al, 2013).

\section{Results}

\section{Types of Internet Facilitated Rape}

The IFRs were categorised via the platform they used to solicit victims, analysis was then conducted to observe the difference in crime scene behaviors exhibited between the groups. However, due to the insufficient frequency counts in the groups: 'advert (Sexual) =10', 'internet chatroom' $=15$ and 'unknown' $=5$ these cases were excluded for this analysis only. Table 2 reports the percent occurrence of each crime scene behavior within the two remaining categories; 'dating site' and 'social networking site'. The highest frequency behaviors displayed by both sets of offenders were 'self-disclosure,' 'offender kisses victims face', and 'offender refers to prolonged relationship', illustrating a potential bias towards attempted 'intimacy'.

Chi-square tests of independence were conducted on the crime scene behaviors $(n=38)$ to expose the behavioral differences between offenders who met their victims through social networking sites and dating sites. Due to multiple hypotheses being tested Bonferroni Holn corrections were implemented ( $\alpha=0.001-0.003$ as a criterion for significance was adopted), with no significant relationships found (see Table 2). Offender 'apologies' and 'offender bites victim' showed approaching significant associations with offenders who use social networking sites compared with those who utilised dating sites. But the remainder of the analyses were nonsignificant, which would suggest that there were no difference between the styles of IFR in terms of the discrete behaviors offenders display. Hence, results provided no motivation to analyse offense styles separately through proceeding research.

Table 2: Behavioral differences between IFRs who chose social networking sites and those who chose dating sites to solicit their victim insert here 


\section{A comparison of Internet Facilitated Rapes and Non-Internet Facilitated Rapes}

The highest occurring behaviors in the IFR sample were 'self disclosure' (75\%) and 'kissed victims face' (63\%) (see Table 3). The behaviors “offender stabs victim", "wears gloves" and "wears a disguise" never occurred in this IFR sample. Chi-square tests of independence were then conducted on each discrete variable $(n=38)$ to observe any behavioral differences across IFR and two non-IFR offenses. In terms of the Confidence comparison sample only one significant relationship was found (see Table 3) revealing that perpetrators who used the Internet within their offense referred to a 'prolonged relationship' at a higher rate (39\%) than confidence offenders who did not use the internet within their offense $(16 \%), \chi^{2}(1, n=288)=18.995, p=0.001$. These offenders also significantly 'disclosed more information about themselves' (75\%, compared with non IFR=59.7\%) $\chi^{2}(1, n=288)=12.43, p=0.006$, but this do not reach the Bonferroni Holn threshold. The results suggest, therefore, that there is a high degree of behavioral similarity between the IFR and the nonIFR confidence offenders.

There were, however, a number of significant differences between the IFR sample and the surprise comparison sample (See Table 3). The behaviors 'self-disclosure', 'kissed victims face', 'offender refers to prolonged relationship', 'compliments the victim' and 'curiosity about victim' were significantly associated with IFRs, whilst in comparison non-IFR Surprise offenders recorded high rates of: 'verbally threatens the victim', wore 'gloves' 'displayed a weapon' and 'threatened the victim with a weapon'.

Chi-square tests of independence were then conducted on each discrete variable $(n=38)$ to observe any behavioral differences across the two non-IFR offenses. As Table 3 shows six of the nine differences between IFR and surprise approach were also found when comparing non-Internet facilitated confidence and surprise approach rapists. Therefore, the results have shown that IFR and confidence rapists were very similar, but were comparatively different from surprise rapists. 
Table 3: Occurrence of crime scene behaviors in the three samples and significant associations insert here

\section{Multidimensional model of Internet Facilitated Rape offense behavior}

An SSA was conducted on 26 discrete crime scene behaviors across the 144 IFR cases in order to observe the underlying relationships between variables (see Figure 1.). Offense behaviors that occurred in less than $5 \%$ or more than $70 \%$ could not be included in the SSA analysis. The SSA revealed a coefficient alienation of 0.29 in 32 iterations, indicating a reasonable fit between the SSA plot and the original association matrix (Baddoo \& Hall, 2002). Each point on Figure 1 represents a crime scene behavior committed by the offender, the distance between behaviors signifies the likelihood of behaviors occurring together, the further variables are from each other the less likely they are to co-occur (Almond et al 2013).

The present study sought to investigate whether the behavior displayed within IFR could be classified according to the three behavioral themes of violence, interpersonal involvement and criminal sophistication. As hypothesised, the associations between behavioral variables, as observed in Figure 1, construct three distinct behavioral themes. These categories were comprised of behaviors that are likely to co-occur and that are thematically similar. Four of the variables, 'fingers inserted into vagina', 'blunt hand', 'implies knowing the victim' and 'refers to victims previous sexual experiences' did not appear in their predicted theme (see Table 1), possible reasons for this will be explored within each theme.

Figure 1: Smallest space analysis of behavioral themes found within Internet Facilitated Rape insert here 
Table 4 illustrates the behavior composition of each of the themes. Within the violence theme, the highest occurring behavior was 'forced participation' (41\%), in the interpersonal involvement theme 'kissing' (63\%) was most frequent and in the criminal sophistication theme 'offender stole property from the victim' (17\%) was the most common behavior displayed. The behaviors within the interpersonal involvement theme all hold high frequencies, suggesting that behaviors within this theme are most common within IFRs.

Table 4. Behavioral composition of the three themes insert here

\section{Criminal Sophistication}

The four behaviors categorised under criminal sophistication/comparison all depict an offender's ability to avoid detection. Behaviors such as 'destroyed forensic evidence' and 'offender wears condom' all illustrate the perpetrator's knowledge and understanding of scientific and technological advances, and reveal the level of planning and consideration taken by the offender to ensure no discriminating evidence could be obtained from the scene. This type of behavior has been associated with serial offenders, through which experience may culminate in more 'criminally aware' behavior (Park et al., 2008). Within this theme 'stole property' was the most common action exhibited, with the offender using the opportunity presented by the sex offense to commit a non-sexual crime. This concurrence lends itself to the construct of experience, implying that the offender has practice in criminal conduct. These behaviors suggest that the offense is predominantly about personal gain and satisfaction and draws parallels to Canter's (1994) 'Victim as object' theme. The verbal behavior 'legal or police procedures mentioned' further suggests an understanding and awareness of the criminal justice system and continues to build an impression of experience, fore-thought and planning. This theme is clearly reflected in the 'criminal sophistication' theme identified by Park et al. (2008) and Corovic et al. (2012). 


\section{Interpersonal Involvement}

The 12 variables that fell within this theme contain distinct interpersonal elements. These behaviors reflect a pattern of attempted intimacy, in which the offender tries to create a relationship and share affection with the victim. Verbal behaviors such as 'compliments victim', 'curiosity', 'reassures victim' 'asks victim to make comments' and 'ingratiating behavior' could all demonstrate the offender's attempt to establish a connection with the victim and create the impression of a consensual sexual experience. Other verbal behaviors that fall within this category, 'offender refers to victim's enjoyment' and offender refers to a 'prolonged' relationship, may assist in constructing the sensation of a normal sexual encounter. Furthermore, the sexual behaviors observed within this theme also hold intimate connotations e.g. 'kissing'. It is also possible that the behaviors of 'cunnilingus' and 'fingers inserted into the vagina' may be seen as an intimate act by the offender themselves, in their attempt to facilitate closeness and consent. The behaviors within this theme closely mirror Canter's (1994) 'victim as person' theme, as well as the 'involvement' theme identified by Canter et al. (2003), Hakkanen et al. (2004) and Santilla et al. (2005). A behavior that was not anticipated to fall within the interpersonal theme was 'blunt hand', however, post-hoc analysis examined the 'level of force' associated with each case of 'blunt hand' and revealed that the majority of these actions (69\%) resulted in 'no' or 'minimal injury'. This could suggest that the offender was using the minimal amount of force needed to ensure his victim cooperated.

\section{Violence}

The violence region at the bottom of the plot in Figure 1 consists of 10 crime scene behaviors that reflect the overtly aggressive interaction between the offender and victim. Crime scene behaviors which fall within this theme, such as 'bite', 'covered mouth' and 'displayed 
weapon' illustrate a high level of physical violence directed at the victim. The verbal behaviors categorised within this theme further extend the idea of violence, variables such as 'verbal threats' carry an overt message of aggression, whereas 'offender implies knowledge of the victim' can be seen as an act of intimidation, reflecting further psychological violence (Almond et al., 2013) rather than an intimate behaviors as previously predicted. The sexual behaviors that fall within this theme also share a clear physical element, for example, 'forced participation', 'fellatio', 'vaginal penetration from rear' and 'anal penetration', which could further demean or degrade the victim.. Offender refers to "victims previous sexual practices" was predicted to reflect a means of gaining intimacy. However this behavior was found to be highly correlated with other violence actions indicating that for these offenders this behavior might be used as a method of humiliating or degrading their victim. The actions categorised within this theme suggest the offense is predominantly about venting anger or frustration as opposed to gaining sexual gratification (Almond et al., 2013), with parallels drawn between this theme and Canters' (1994) 'Victim as vehicle' classification. This theme can also be likened to the theme of 'Hostility' identified by Canter et al. (2003) and Hakkanen, Lindlof and Santtila (2004), and the 'Violence' theme recognised by Park et al. (2008). 'Offender masturbates' was found within the violence theme, which could be seen as an action intended to degrade or frighten the victim, hence its position within the violence theme.

\section{Dominant theme analysis}

An offense may involve behaviors from more than one theme, but as they are psychologically distinct it is hypothesised that the majority of cases will reflect one dominant theme. In order to identify dominant themes of behavior the same criteria used by Almond et al. (2006) was adopted. Here the percentage of occurrence of the variables in the dominant theme has to be greater than the sum of the percentage occurrence for the other two themes. Employing this technique, $71 \%$ (103 of 144) of cases could be classified as displaying dominant criminal 
sophistication, $12 \%$ (17), interpersonal involvement, $40 \%$ (58) and violence, $19 \%$ (28). There were twice as many dominant interpersonal involvement offenders (40\%) as opposed to the next most frequently occurring dominant theme, violence $19 \%$ ).

\section{Discussion}

Literature surrounding IFR has predominantly focused on investigating the techniques offenders employ to select and seduce victims into offline encounters (Malesky, 2007; Noll et al., 2009). This research tends to focus on child victims and has yet to investigate overt crime scene behaviors particularly within adult victim populations. Previous literature investigating offense behavior displayed within non-IFR cases has shown that sex offenders are not a homogenous group of perpetrators (Canter, 1994). Research has identified diverse themes of rape behavior, allowing investigators to differentiate between offenders based on their distinct interaction style (Canter et al., 2003). Whilst these behavioral classification models differ slightly in their general themes and their labels, when taken together, research endorses three main themes: violence, interpersonal involvement and criminal sophistication (e.g. Canter et al., 2003; Corovic et al., 2012; Park et al., 2008; Santtila et al., 2005). The present study looked to investigate the offense behaviors displayed within IFR cases, first by examining behaviors across the platforms offenders used to solicit their victims, second, by comparing IFR and non-IFR cases, and finally by examining the underlying structure of IFR offense behavior using an SSA.

Using a sample of 144 IFR cases, analysis explored behavioral differences between offenders who used dating sites, or social networking sites to solicit their victims, however, no significant results were found. This finding suggests that the platforms offenders used to meet their victims were not suggestive of the behavior they were likely to display within the rape itself. A larger sample across the various platforms may assist in any further work in this area, as due to the small numbers within the groupings, analysis was only conducted on those using dating websites and social networking sites to solicit their victim. As indicated by the recent National Crime 
Agency (2016) report, the various platforms used are increasing, with their own descriptive analysis indicating that their sample of offenders used over 40 different Internet sites and applications. The examination of these platforms in terms of the interactions, demographic information of both victims and offenders and most importantly risk of sexual abuse, requires further understanding to enable early protection and prevention of sexual abuse.

Analysis then took two comparative samples of age matched non-IFR cases (confidence and surprise approach) to explore any behavioral differences in the rape crime scene between those offenses committed online (IFR) and offline (non-IFR). The first stage of the analysis found only one significant result (due to Bonferroni Holn corrections). This result found that offenders that referred to a 'prolonged relationship' whilst committing the rape, was observed at a higher rate in IFR cases than in non-IFR confidence cases. Taking this finding, along with the marginally nonsignificant finding of increased self - disclosure of IFRs, this supports initial findings within the recent National Crime Agency (2016) report regarding the possible mismatch between expectations of victims and offenders when meeting face-to-face. They discussed how online disinhibition allows victims to engage in sexual communication quicker than offline dating interactions, and this trust and quick development of the relationship may lead to the offender believing that sexual consent has been agreed before meeting. This process within communications online has also been extensively explored in relation to grooming and rapport building.

Research indicates that generally individuals reveal more about themselves online than offline (Krasnova, Spiekermann, Koroleva \& Hildebrand, 2010). The grooming process online is often highly individualised (Sheehan \& Sullivan, 2010), with offenders adapting their grooming strategies individually to suit their victim (Craven et al., 2006). Offenders often invest a significant amount of time and effort in establishing a relationship and building up trust in gaining sexual compliance of a victim (Sullivan \& Beech, 2004). The nature of sexual grooming makes detection difficult, as the intimate nature of the interactions are used to gain trust in the victim to avoid any disclosures to friends or family (Craven, Brown \& Gilchrist, 2006). Therefore, a key finding within 
this comparison between IFR and non-IFR confidence may be the likely higher frequency and nature of conversation (increased self-disclosure and refers to prolonged relationship), which may indicate the importance of rapport building within IFR cases. Besides this specific result, IFRs and non-IFR confidence offenders were shown to be behaviorally consistent.

The second stage of the analysis compared IFRs to non-IFR surprise cases found nine significant differences, indicating that these offenders were considerably different from each other in terms of the rape crime scene behaviors. IFRs were found to have significantly higher presence of self disclosure, kissed victims face, refers to prolonged relationship, curiosity about victim and compliments the victim; all behaviors which may indicate the offenders attempt to gain 'intimacy' with their victim (Almond et al, 2013; Canter et al, 2003,). The non-IFR surprise sample has significantly higher presence of 'verbally threatens victim', 'wore gloves', 'threatened with a weapon' and displayed weapon' behaviors indicating increased aggression or criminal sophistication (Almond, et al, 2013; Canter et al, 2003,).

The third stage of the analysis compared the two non-IFR samples with six significant differences found. Non-IFR confidence offenders had higher presence of 'self disclosure', 'kissed victims face' and 'curiosity about victim', than non-IFR surprise offenders. As with IFRs these behaviors indicated the offenders attempt to gain 'intimacy with their victim (Canter et al, 2003; Almond et al, 2014). The non-IFR surprise offenders had a higher presence of 'verbally threatens victim'; 'wore gloves', and 'threatened with a weapon' as previous stated this indicates the offenders aggression or criminal sophistication (Almond, et al, 2013; Canter et al, 2003,). Therefore, the results indicated clear differences in the behaviors displayed by confidence and surprise non-IFR offenders, with behavioural similarities between non-IFR confidence and IFRs. Thus, this may indicate that the method of approach used by a stranger rapist has a significant effect on the subsequent rape crime scene behavior displayed, regardless of any prior contact.

MDS analysis was then conducted on the IFR sample to investigate the behavioral structures displayed by offenders. The SSA revealed three distinct themes of behavior that could be defined as 
violence, interpersonal involvement and criminal sophistication. Using the criteria employed by Almond et al. (2006) $71 \%$ of cases could be assigned to one dominant behavioral theme. This result lends support to the present model of offense behavior in its pragmatic ability to represent the underlying structure of IFR.

The presence of three distinct behavioral themes suggests that IFRs, similar to non-IFRs, are a heterogeneous group. Differentiation between offenders signifies the diversity between their motivations, where the offense serves a different purpose for each perpetrator. Offenders categorised within the violence theme used the victim as a vehicle to vent their anger, exerting violence upon their victim. Whereas the criminal sophisticated theme was about the offender gaining sexual gratification. Here, the perpetrator had planned the attack and demonstrated 'criminal awareness', eluding to experience. However, the most frequent theme exhibited was interpersonal involvement, in that the offenders' primary motivation was to form an intimate relationship and share an affectionate sexual experience with the victim. This theme occurred at a greater rate than the other two themes combined, behaviors categorised under interpersonal involvement also held the highest frequency signifying a high level of occurrence.

In previous literature on non-IFR, the variable 'confidence approach' (where the offender gains the victim's confidence) has been categorised within the interpersonal theme (Corovic et al., 2012; Park et al., 2008; Santtila et al., 2005). It is, therefore, not surprising that there were a high percentage of dominant interpersonal involvement IFRs given their similarity with non-IFR confidence approach offenders. After meeting their victim online and developing some form of prior relationship, these offenders then continue to attempt "intimacy' during the rape offense, again reiterating the initial descriptive analysis within the National Crime Agency (2016) report.

\section{Limitations}

Whilst the sample was derived from the SCAS UK database, which arguably offers a comprehensive, representative and contemporary sample of rape cases within the UK, rape 
continues to be largely under reported (Myhill \& Allen, 2002), with current estimations stating that current rape figures account for only $17 \%$ of the true figure (ONS, 2015). This sample only contained cases which met the SCAS criteria for submission and as such may potentially be skewed. Whilst stranger rape cases are reported at a greater rate (Bachman, 1993; Hodge \& Canter, 1998; Williams, 1984), the sample obtained represents only a small proportion of offenders who commit sex crimes. Furthermore, the inability to detect criminal sophistication themes due to offenders' 'criminal awareness' may also reflect the skewed rates observed. In contrast, violence themes may be easier to detect and convict in court, showing the slightly higher occurrence. Hence, a sample collected from other sources, such as rape charities and drop-in clinics may report different ratios of dominant themes; however, the underlying structure of the offense behaviors should stay consistent as they were psychologically distinct (Almond \& Canter, 2007). By taking a sample from the SCAS database, the present study tackles common limitations of small sample size and poor quality data. However, as data was not initially collected for the primary purpose of research, it may be vulnerable to reporting errors and omissions. Researchers attempted to overcome this inaccuracy by the analytical frame work adopted, for example, Jaccard's coefficient. The sample was limited to female victims and male offenders, therefore, the sample lacked diversity in terms of gender of victim, offender and sexual orientation. Future research would need to consider other sexual orientations, male victims and female offenders.

\section{Implications}

The role of a Behavioral Investigative Advisor (BIA) is to provide evidence-based strategies for tackling serious crime (Rainbow, 2008). To ensure the advice they formulate holds sufficient strength, Toulmin's philosophy of argument is adopted, where appropriate backing is needed to satisfy the 'conclusion' of an argument (Alison, Smith, Eastman \& Rainbow, 2001). In this context, backing consists of empirical research into criminal behavior. Effective classification systems have previously been seen to assist, direct and support Comparative Case Analysis (CCA) and BIAs in 
their decision making, thus making more effective use of their limited resources and ultimately facilitating the detection and conviction of offenders (Yokota \& Canter, 2004). Within this exploratory study, the results may provide the first steps in further understanding IFR crime scene behaviors. The ability to link crime reduces the number of suspects, whilst also accumulating evidence concerning the offender, leading to more efficient and productive investigation strategies (Santtila et al., 2005). To further this research a sample consisting of serial sex offenders that commit both IFR and non-IFR could be examined to investigate the behavioral consistency across offenses, in terms of discrete behaviors and thematic classifications.

\section{Conclusions}

This study has highlighted that within the current IFR sample, the platform used to solicit victims did not impact on the rape crime scene behaviors displayed. However, due to reduced comparisons across the various platforms, further work should seek to explore this in more detail, to ensure appropriate education and prevention of sexual abuse when engaging in Internet dating and social interaction. In addition, when exploring the IFR group to the non-IFR comparison groups, behavioral similarities were found between the IFRs and non-IFR confidence offenders, with both groups differing from the non-IFR surprise stranger rapists. Thus, this suggests that the method of approach within the crime scenes of stranger rapists may better inform the type of offender they are, rather than the interaction between the victim and offender prior to the offense. Finally, analysis showed that although IFRs have a tendency towards attempted intimacy, they were a heterogeneous group of offenders with their crime scene actions classified according to the three distinct behavioral themes: criminal sophistication, interpersonal involvement and violence. The differences between the themes signifies the diversity between the offenders' motivations, moreover, the offense serves a different purpose for each perpetrator e.g. expression of aggression, experience of intimacy, or sexual gratification. These exploratory results provide some first steps in understanding IFRs regarding the use of solicitation platforms and their behavioral similarities and differences to 
other non-IFR stranger rapists. These initial findings may assist CCA's and BIA's within their investigations. Importantly, the current study has identified an area of research that requires further attention and has established a solid platform from which extended research and investigation can be launched. 


\section{References}

Alison, L, J., Smith, M. D., Eastman, O., \& Rainbow, L. (2001). Toulmin's philosophy of argument and its relevance to offender profiling. Psychology, Crime and Law, 9, 173-184.

Almond, L., \& Canter, D. V. (2007). Youths who sexually harm: A multivariate model of behavior. Journal of Sexual Aggression, 13, 217-233.

Almond, L., Canter, D. V., \& Salfati, C. G. (2006). Youths who sexually harm: A multivariate model of characteristics. Journal of Sexual Aggression, 12, 97-114.

Almond, L., McManus, M. A., \& Ward, L. (2013). Male-on-male sexual assaults: An analysis of crime scene actions. Journal of interpersonal violence, 29, 1279-1296.

Bachman, R. (1993). Predicting the reporting of rape victimizations. Have rape reforms made a difference? Criminal Justice and Behavior, 20, 254-270.

Baddoo, N., \& Hall, T. (2002). Software process improvement Motivators: An analysis using Multidimensional Scaling. Empirical Software Engineering, 7, 93-114.

Canter, D. V. (1994). Criminal shadows. London: Harper Collins.

Canter, D. V., \& Heritage, R. (1990). A multivariate model of sexual offense behavior: Developments in 'offender profiling'. The Journal of Forensic Psychiatry, 1, 185-212.

Canter, D. V., Bennell, C., Alison, L. J., \& Reddy, S. (2003). Differentiating sex offenses: A behaviorally based thematic classification of stranger rapes. Behavioral Sciences and the Law, 21, 157-174.

Canter, D., \& Youngs, D. (2003). Beyond 'Offender Profiling: The Need for an Investigative Psychology. In D. Carson, \& R. Bull (eds.), Handbook of psychology in legal contexts( pp. 171-205). New York: Wiley.J.

Canter, D. \& Youngs, D. (2008). Applications of Geographical Profiling, Ashgate Publishing

Corovic, J., Christianson, A., \& Bergman, L.R. (2012). From crime scene actions in stranger rape to prediction of rapist type: Single-victim or serial rapist? Behavioral Sciences and the Law, 30, 764-781. 
Craven, S., Brown, S., \& Gilchrist, E. (2006). Sexual grooming of children review of literature and theoretical considerations. Journal of Sexual Aggression, 12(3),287-299.

Davies, A. (1992). Rapists' behavior: A three aspect model as a basis for analysis and the identification of serial crime. Forensic Science International, 55, 173-194.

Davies, A. (1997). Specific profile analysis: A data-based approach to offender profiling. In J.L. Jackson, \& D.A. Bekerian (Eds.), Offender profiling: Theory, research and practise (pp.191-270). New York: Wiley.

Groth, A. N. (1979) Men Who Rape: The Psychology of the Offender. New York: Plenum Press.

Groth, A. N., Burgess, A. W., \& Holmstrom, L. L. (1977). Rape: Power, anger, and victims: sexuality. American Journal of Psychiatry, 134, 1239- 1243.

Häkkänen, H., Lindlöf, P., \& Santtila, P. (2004). Crime scene actions and offender characteristics in a sample of Finnish stranger rapes. Journal of Investigative Psychology and Offender Profiling, 1, 17-32.

Hazelwood, R.R., \& Burgess, A.W. (2001). The behavioral oriented interview of rape victims: The key to profiling. In R.R Hazelwood, \& A.W. Burgess (Eds.), Practical aspects of rape investigation: A multidisciplinary approach. (3rd ed.) (pp.115-131). Boca Raton: CRC Press.

Hodge, S., \& Canter, D. (1998). Victims and perpetrators of male sexual assault. Journal of Interpersonal Violence, 13, 222-239.

Knight, R.A., \& Prentky, R.A. (1990). Classifying sexual offenders: The development and collaboration of taxonomic models. In. W.L. Marshall, D.R. Laws, \& H.E. Barbaree (Eds.), Handbook of Sexual Assault: Issues, Theories and Treatment of the offenders (p. 23-52). New York: Plenum Press.

Krasnova, H., Spiekermann, S., Koroleva, K., \& Hildebrand, T. (2010). Online social networks: why we disclose. Journal of Information Technology, 25(2), 109-125. 
Malesky, L. A. (2007). Predatory online behavior: Modus operandi of convicted sex offenders in identifying potential victims and contacting minors over the Internet. Journal of child sexual abuse, 16, 23-32.

Marshall, W.L. (1989). Intimacy, loneliness and sexual offenders. Behavioral Research in Therapy, 27, 491-503.

McManus, M., Almond, L., Cubbon, B., Boulton, L. \& Mears, I (2016), Exploring the online communicative themes of child sex offenders. Journal of Investigative Psychology and Offender Profiling, 13, 166-179.

Myhill, A., \& Allen, J. (2002). Rape and sexual assault of women: The extent and nature of the problem. Home Office Research Study 237. London: Home Office.

National Crime Agency. (2016). Emerging new threat in online dating: Initial trends in internet dating-initiated serious sexual assaults. London: National Crime Agency. Accessed $7^{\text {th }}$ September 2016 from: http://www.nationalcrimeagency.gov.uk/publications/670-emerging$\underline{\text { new-threat-in-online-dating-initial-trends-in-internet-dating-initiated-serious-sexual- }}$ $\underline{\text { assaults/file }}$

Noll, J.G., Shenk, C.E., Barnes, J.E., \& Putnam, F.W. (2009). Childhood abuse, avatar choices, and other risk factors associated with Internet-initiated victimization of adolescent girls. Pediatrics, 123, 1078-1083.

Palermo, G. B. (2003). Faces of violence (2nd ed.). Springfield, IL: Charles C Thomas.

Park, J., Schlesinger, L. B., Pinizzoto, A. J., \& Davis, E. F. (2008). Serial and single-victim rapists: Differences in crime-scene violence, interpersonal involvement and criminal sophistication. Behavioral Sciences and the Law, 26, 227-237.

Rainbow, L. (2008). Taming the beast: The UK approach to the management of behavioral investigative advice. Journal of Police and Criminal Psychology, 23, 90-97.

Rosenfeld, M.J., \&Thomas, R.J. (2012). Searching for a Mate: The Rise of the Internet as a Social Intermediary. American Sociological Review, 77, 523-547. 
Santtila, P., Junkkila, J., \& Sandnabba, N. K. (2005).Behavioral linking of stranger rapes. Journal of Investigative Psychology and Offender Profiling, 2, 87-103.

Seidman, B. T., Marshall, W. L., Hudson, S. M., \& Robertson, P. J. (1994). An examination of intimacy and loneliness in sex offenders. Journal of Interpersonal Violence, 9, 518-534.

Sheehan, V. \& Sullivan, J. (2010). A qualitative analysis of child sex offenders involved in the manufacture of indecent images of children. Journal of Sexual Aggression, $\quad 16(2)$, 143-167.

Sullivan, J. \& Beech, A.R (2004). Assessing Internet Sex Offenders. In M. Calder (Ed.), Child Sexual Abuse and the Internet: Tackling the New Frontier (pp. 69-83). Dorset, UK: Russell House Publishing Limited.

The Guardian. (2015, 12 August). How many Tinder users are married? Fact-checking the app's tweet storm. Accessed 1 September from: = https://www.theguardian.com/technology/2015/aug/12/tinder-vanity-fair-twitter-storm-fact checking

Walsh, W. A., \& Wolak, J. (2005). Nonforcible Internet-related sex crimes with adolescent victims: Prosecution issues and outcomes. Child Maltreatment, 10, 260-271.

Wolak, J., Finkelhor, D., Mitchell, K.J., \& Ybarra, L.M. (2008). Online "Predators" and Their Victims Myths, Realities, and Implications for Prevention and Treatment. American Psychological Association, 63, 111-128.

Wolak, J., Finkhelhor, D., \& Mitchell, K. (2009). Trends in Arrests of Online Predators. Crimes against Children Research Center. 
Table 1. Behavioral variables under their predicted theme with supporting literature

\begin{tabular}{|c|c|c|}
\hline Theme & Variable & Reference \\
\hline Criminal & Destroyed forensic evidence & $4 ; 7$ \\
\hline \multirow{9}{*}{ Sophistication } & Legal or police procedures mentioned & 2 \\
\hline & Offender blindfolds victim & 4 \\
\hline & Offender bound victim & $4 ; 7$ \\
\hline & Offender steals property & 4 \\
\hline & Offender wears condom & 4 \\
\hline & Offender wears disguise & 4 \\
\hline & Offender wears gloves & $4 ; 7$ \\
\hline & Victim forced to bathe & 4 \\
\hline & Victim gagged by restraint & 7 \\
\hline Interpersonal & Cunnilingus performed & 3 \\
\hline \multirow[t]{13}{*}{ Involvement } & Ingratiating behavior & 5 \\
\hline & Offender apologises & 5 \\
\hline & Offender compliments victim & $3 ; 6$ \\
\hline & Offender curiosity & $5 ; 6$ \\
\hline & Offender implies knowing victim & $3 ; 6$ \\
\hline & Offender kisses victim's face & $3 ; 6$ \\
\hline & Offender masturbates self & 2 \\
\hline & Offender reassures victim & $5 ; 6$ \\
\hline & $\begin{array}{l}\text { Offender refers to a prolonged } \\
\text { relationship }\end{array}$ & $5 ; 7$ \\
\hline & Offender refers to victim's enjoyment & 2 \\
\hline & $\begin{array}{l}\text { Offender refers to victim's previous } \\
\text { sexual practises }\end{array}$ & 2 \\
\hline & Self-disclosure & $5 ; 6$ \\
\hline & Victim forced to make comments & $6 ; 7$ \\
\hline \multirow[t]{14}{*}{ Violence } & Anal penetration & $1 ; 3 ; 6$ \\
\hline & Blunt hand force & $4 ; 7$ \\
\hline & Blunt kick & $4 ; 7$ \\
\hline & Fingers placed into vagina & 6 \\
\hline & Manual gagging & 8 \\
\hline & Offender bites victim & 6 \\
\hline & Offender rips victim's clothes & $1 ; 3$ \\
\hline & Offender stabs victim & 7 \\
\hline & Vaginal penetration from rear & 6 \\
\hline & Verbal cruelty directed at victim & $1 ; 7$ \\
\hline & Verbal threats made to victim & $6 ; 7$ \\
\hline & Victim forced to participate & $1 ; 3 ; 6$ \\
\hline & Victim performed fellatio & $1 ; 3 ; 6$ \\
\hline & Weapon displayed & $2 ; 6 ; 7$ \\
\hline
\end{tabular}

1=Alison \& Stein, 2001; 2=Almond et al., 2013; 3=Canter et al., 2003; 4=Corovic et al., 2012; 5=Davies, 1992; 6=Hakkanen et al., 2004; 7=Park et al., 2008; 8=Santilla et al., 2005 
Table 2. Behavioral differences between IFRs who chose social networking sites and those who chose dating sites to solicit their victim

\begin{tabular}{|c|c|c|c|}
\hline Variable & $\begin{array}{l}\text { Dating site } \% \\
\text { occurrence } \\
\mathrm{N}=52\end{array}$ & $\begin{array}{l}\text { Social networking } \\
\text { occurrence } \% \\
\mathrm{~N}=62\end{array}$ & $\mathrm{P}$ value \\
\hline Offender apologises & 7.7 & 22.6 & 0.030 \\
\hline Offender bites victim & 5.8 & 19.4 & 0.033 \\
\hline Victim forced to participate & 30.8 & 43.5 & 0.161 \\
\hline Ingratiating behavior & 15.4 & 25.8 & 0.174 \\
\hline Verbal threats made to victim & 13.5 & 22.6 & 0.211 \\
\hline Offender masturbates self & 17.3 & 9.7 & 0.230 \\
\hline Offender kisses victim's face & 57.7 & 67.7 & 0.268 \\
\hline Offender curiosity & 28.8 & 38.7 & 0.269 \\
\hline Manual gagging & 1.9 & 0 & 0.273 \\
\hline Offender blindfolds victim & 1.9 & 0 & 0.273 \\
\hline Victim gagged by restraint & 1.9 & 0 & 0.273 \\
\hline Offender rips victim's clothes & 7.7 & 3.2 & 0.287 \\
\hline Victim forced to make comments & 5.8 & 11.3 & 0.299 \\
\hline Offender refers to a prolonged relationship & 34.6 & 43.5 & 0.331 \\
\hline Self-disclosure & 78.8 & 71.0 & 0.336 \\
\hline Blunt kick & 0 & 1.6 & 0.358 \\
\hline Victim performed fellatio & 32.7 & 40.3 & 0.400 \\
\hline Verbal cruelty directed at victim & 3.8 & 2.6 & 0.458 \\
\hline Fingers placed into vagina & 23.1 & 29.0 & 0.472 \\
\hline Weapon displayed & 5.8 & 3.2 & 0.509 \\
\hline Legal or police procedures mentioned & 3.8 & 6.5 & 0.535 \\
\hline Offender wears condom & 9.6 & 12.9 & 0.582 \\
\hline Offender compliments victim & 25.0 & 21.0 & 0.609 \\
\hline Offender refers to victim's enjoyment & 21.2 & 17.7 & 0.646 \\
\hline Destroyed forensic evidence & 1.9 & 3.2 & 0.665 \\
\hline Offender bound victim & 1.9 & 1.6 & 0.665 \\
\hline Anal penetration & 30.8 & 27.4 & 0.694 \\
\hline Cunnilingus performed & 11.5 & 9.7 & 0.747 \\
\hline Vaginal penetration from rear & 23.1 & 21.0 & 0.786 \\
\hline Offender implies knowing victim & 5.8 & 4.8 & 0.825 \\
\hline Offender reassures victim & 19.2 & 17.7 & 0.838 \\
\hline $\begin{array}{l}\text { Offender refers to victim's previous sexual } \\
\text { practises }\end{array}$ & 15.4 & 14.5 & 0.897 \\
\hline Victim forced to bathe & 1.9 & 1.6 & 0.900 \\
\hline Offender steals property & 15.4 & 16.1 & 0.914 \\
\hline Blunt hand force & 13.5 & 12.9 & 0.930 \\
\hline Offender stabs victim & 0 & 0 & - \\
\hline Offender wears gloves & 0 & 0 & - \\
\hline Offender wears disguise & 0 & 0 & - \\
\hline
\end{tabular}


Table 3: Occurrence of crime scene behaviors in the three samples and significant associations

\begin{tabular}{|c|c|c|c|c|c|c|}
\hline Variable & $\begin{array}{l}\text { IFR \% } \\
\mathrm{N}=144\end{array}$ & $\begin{array}{l}\text { Con \% } \\
\mathrm{N}=144\end{array}$ & $\begin{array}{l}\text { Surprise } \% \\
\mathrm{~N}=144\end{array}$ & $\begin{array}{c}\text { IFR } \\
\text { v's } \\
\text { Con } \\
\text { p value }\end{array}$ & $\begin{array}{c}\text { IFR } \\
\text { v's } \\
\text { Surp } \\
\text { p value }\end{array}$ & $\begin{array}{c}\text { Con } \\
\text { v's } \\
\text { Surp } \\
\text { p value }\end{array}$ \\
\hline Self-disclosure & 75.0 & 59.7 & 22.2 & .006 & $<.001$ & $<.001$ \\
\hline $\begin{array}{l}\text { Offender kisses victim’s } \\
\text { face }\end{array}$ & 63.2 & 55.6 & 21.5 & & $<.001$ & $<.001$ \\
\hline Victim forced to participate & 41.0 & 39.6 & 36.8 & & & \\
\hline $\begin{array}{l}\text { Offender refers to a } \\
\text { prolonged relationship }\end{array}$ & 38.9 & 16.0 & 8.3 & .001 & $<.001$ & \\
\hline Offender curiosity & 37.5 & 42.4 & 19.4 & & .001 & $<.001$ \\
\hline Victim performed fellatio & 36.8 & 36.8 & 32.6 & & & \\
\hline Anal penetration & 30.6 & 22.2 & 19.4 & & & \\
\hline Fingers placed into vagina & 27.8 & 33.3 & 28.5 & & & \\
\hline $\begin{array}{l}\text { Offender compliments } \\
\text { victim }\end{array}$ & 21.5 & 19.4 & 9.0 & & .003 & \\
\hline $\begin{array}{l}\text { Vaginal penetration from } \\
\text { rear }\end{array}$ & 21.5 & 24.3 & 15.3 & & & \\
\hline $\begin{array}{l}\text { Verbal threats made to } \\
\text { victim }\end{array}$ & 20.1 & 27.8 & 45.1 & & $<.001$ & .002 \\
\hline Ingratiating behavior & 18.8 & 20.8 & 10.4 & & & \\
\hline $\begin{array}{l}\text { Offender refers to victim's } \\
\text { enjoyment }\end{array}$ & 18.8 & 14.6 & 10.4 & & & \\
\hline Offender reassures victim & 18.8 & 18.8 & 17.4 & & & \\
\hline Offender steals property & 16.7 & 15.3 & 24.3 & & & \\
\hline Offender apologises & 15.3 & 8.3 & 9.7 & & & \\
\hline $\begin{array}{l}\text { Offender refers to victim's } \\
\text { previous sexual practises }\end{array}$ & 14.6 & 9.0 & 9.7 & & & \\
\hline Blunt hand force & 14.6 & 21.5 & 22.9 & & & \\
\hline Offender masturbates self & 13.9 & 11.8 & 13.2 & & & \\
\hline Offender wears condom & 13.9 & 14.6 & 6.3 & & & \\
\hline Offender bites victim & 13.2 & 7.6 & 5.6 & & & \\
\hline Cunnilingus performed & 12.5 & 10.4 & 7.6 & & & \\
\hline $\begin{array}{l}\text { Victim forced to make } \\
\text { comments }\end{array}$ & 9.0 & 7.6 & 9 & & & \\
\hline $\begin{array}{l}\text { Legal or police procedures } \\
\text { mentioned }\end{array}$ & 6.3 & 5.6 & 4.2 & & & \\
\hline $\begin{array}{l}\text { Destroyed forensic } \\
\text { evidence }\end{array}$ & 6.3 & 4.9 & 6.3 & & & \\
\hline $\begin{array}{l}\text { Offender implies knowing } \\
\text { victim }\end{array}$ & 6.3 & 7.6 & 3.5 & & & \\
\hline Weapon displayed & 5.6 & 11.1 & 16.7 & & .003 & \\
\hline $\begin{array}{l}\text { Offender rips victim's } \\
\text { clothes }\end{array}$ & 4.2 & 11.1 & 11.8 & & & \\
\hline Offender bound victim & 3.5 & 3.5 & 2.1 & & & \\
\hline $\begin{array}{l}\text { Verbal cruelty directed at } \\
\text { victim }\end{array}$ & 2.8 & 5.6 & 2.8 & & & \\
\hline Threatened with weapon & 2.8 & 1.4 & 13.2 & & .001 & $<.001$ \\
\hline Victim gagged by restraint & 1.4 & 0.7 & 1.4 & & & \\
\hline Victim forced to bathe & 1.4 & 0.7 & 2.1 & & & \\
\hline
\end{tabular}




\begin{tabular}{lccccc} 
Offender blindfolds victim & 0.7 & 0 & 2.8 & & \\
Blunt kick & 0.7 & 2.8 & 3.5 & & \\
Offender stabs victim & 0 & 1.4 & 0.7 & $<.001$ & $<.001$ \\
Offender wears gloves & 0 & 0.7 & 9.7 & & \\
Offender wears disguise & 0 & 0.7 & 4.2 & \\
\hline
\end{tabular}


Table 4. Behavioral composition of the three themes

\begin{tabular}{|c|c|c|c|}
\hline Theme & Name & Explanation & $\mathrm{n}(\%)$ \\
\hline \multirow{4}{*}{$\begin{array}{l}\text { Criminal } \\
\text { Sophistication }\end{array}$} & StoleP & Offender steals property & $24(17)$ \\
\hline & Condom & Offender wears condom & $20(14)$ \\
\hline & DestroyedF & Destroyed forensic evidence & $9(6)$ \\
\hline & Legal & Legal or Police procedures mentioned & $9(6)$ \\
\hline \multirow{12}{*}{$\begin{array}{l}\text { Interpersonal } \\
\text { Involvement }\end{array}$} & Kissing & Offender kisses victim's face & $91(63)$ \\
\hline & ProlongR & $\begin{array}{l}\text { Offender refers to a prolonged } \\
\text { relationship }\end{array}$ & $56(39)$ \\
\hline & Curiosity & Offender curiosity & $54(38)$ \\
\hline & FintoV & Fingers placed into vagina & $40(28)$ \\
\hline & Compliments & Offender compliments victim & $31(22)$ \\
\hline & IngratiatingB & Ingratiating behavior: advice, kindness & $27(19)$ \\
\hline & ReassuresV & Offender reassures victim & $27(19)$ \\
\hline & VictEnj & Offender refers to victim's enjoyment & 27 (19) \\
\hline & Apologises & Offender apologises & $22(15)$ \\
\hline & BluntH & Blunt hand force & $21(15)$ \\
\hline & Cunnilingus & Cunnilingus performed & $18(13)$ \\
\hline & VComments & Victim forced to make comments & $13(9)$ \\
\hline \multirow[t]{10}{*}{ Violence } & ForcedP & Victim forced to participate & $59(41)$ \\
\hline & Fellatio & Victim performed fellatio & $53(37)$ \\
\hline & AnalP & Anal penetration & $44(31)$ \\
\hline & VaginalPR & Vaginal penetration from the rear & $31(22)$ \\
\hline & VerbalT & Verbal threats made to victim & $29(20)$ \\
\hline & Vsex & $\begin{array}{l}\text { Offender refers to victim's previous } \\
\text { sexual practise's }\end{array}$ & $21(15)$ \\
\hline & OMasturbates & Offender masturbates self & $20(14)$ \\
\hline & Bite & Offender bites victim & $19(13)$ \\
\hline & KnowV & Offender implies knowing victim & $9(6)$ \\
\hline & WeaponD & Weapon displayed & $8(6)$ \\
\hline
\end{tabular}


Figure 1. Smallest space analysis of behavioral themes found within Internet facilitated rape

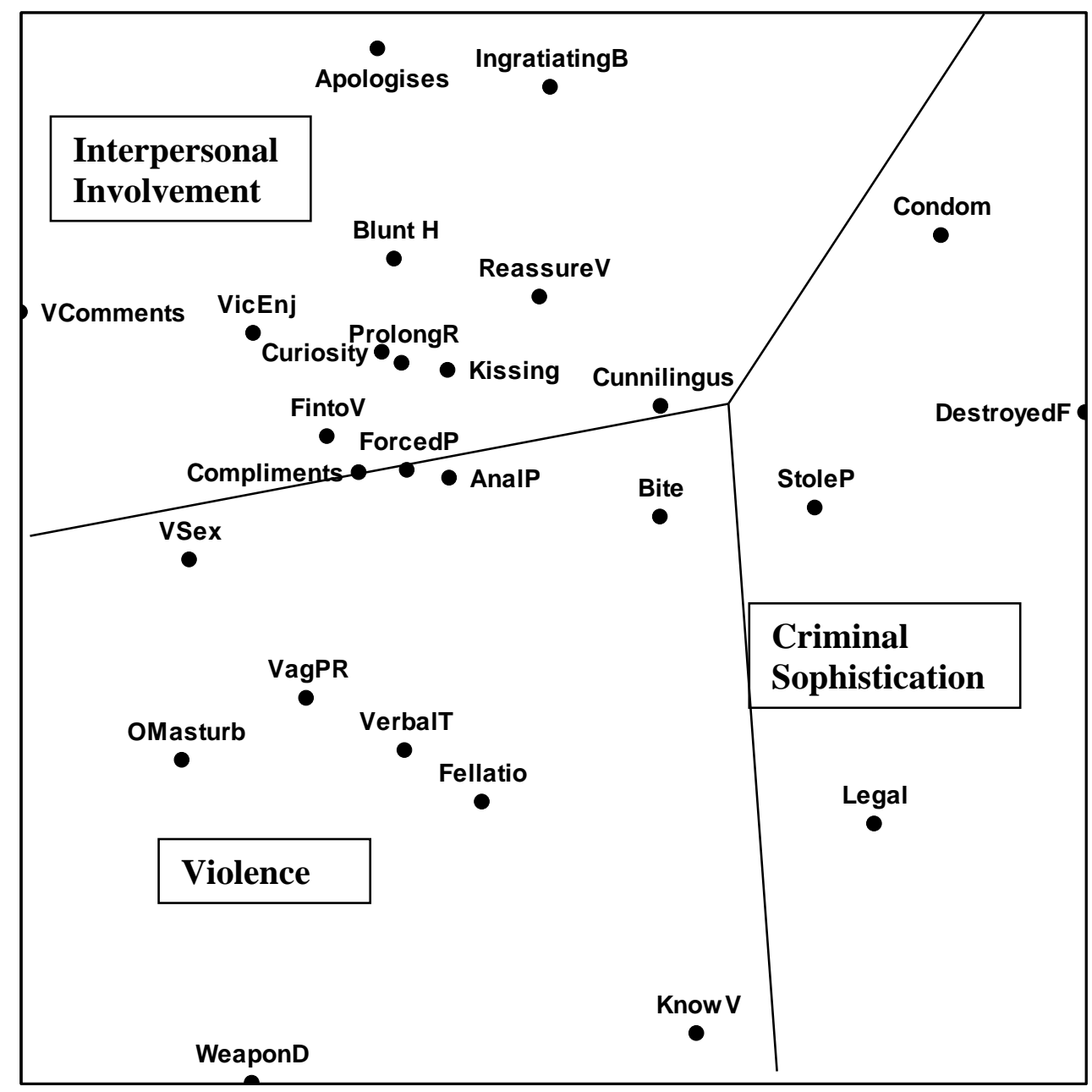

